\title{
Outsourcing and Wage Inequality in a Dynamic Product Cycle Model
}

\author{
Selin Sayek and Fuat Şener*
}

\begin{abstract}
This paper constructs a dynamic North-South trade model with outsourcing and endogenous innovation. Production of high quality goods is first performed in the North (Northern phase), then split between the North and the South (Outsourcing phase), and finally shifted to the South (Southern phase). This cycle is reignited whenever a Northern firm innovates a higher quality product. We find that an increase in the fraction of outsourced production raises the Northern skill premium unambiguously, while raising the Southern skill premium if and only if the skill intensity of outsourced production is higher than that of local Southern production.
\end{abstract}

\section{Introduction}

Over the past two decades, the relative position of less-skilled workers has deteriorated in the North (developed countries). In the US, between the late 1970s and early 1990s, the college/high school wage premium has increased from $45 \%$ to $80 \%$ (Topel, 1997). In OECD Europe, there was a mild increase in skill premia but a substantial surge in the unemployment, mostly concentrated among the unskilled. On the other hand, skill premia trends in the South (developing countries) present a mixed picture. In Mexico, between 1985 and 1989, the relative wage gap between skilled and unskilled labor increased by 15\% (Feenstra and Hanson, 1997); in Chile, between 1980 and 1990, the college wage premium increased by $56.4 \%$ (Robbins, 1996). However, in Singapore between 1966 and 1980 and in Mexico between 1978 and 1985, the skill premia have actually decreased (Wood, 1994; Feenstra and Hanson, 1997).

The literature on wage inequality predominantly focuses on Northern countries, offering two explanations: increased trade (Leamer, 1993, 1994; Borjas and Ramey, 1995) and skill-biased technological change (Lawrence and Slaughter, 1993; Berman, Bound and Grilliches, 1994). Most of the existing studies have analyzed the role of trade through the lens of the Heckscher-Ohlin (henceforth HO) model. This model predicts that increased trade between a skilled-labor-abundant North and an unskilledlabor-abundant South (i) raises the prices of skilled-labor-intensive goods in the North and reduces the relative price of unskilled-labor-intensive goods in the South, (ii) leads to an increase in the Northern skill premium and a decrease in the Southern skill premium (the Stolper-Samuelson theorem), and (iii) within each industry causes an

\footnotetext{
*Sayek: Department of Economics, Bilkent University, Ankara, Turkey. Tel: +90-312-290-1406; E-mail: sayek@bilkent.edu.tr. Sener: Department of Economics, Union College, Schenectady, NY 12308, USA. Tel: +1-518-388-7093; E-mail: senerm@union.edu. An earlier version of this paper has been circulated under the title "Dynamic Effects of Outsourcing on Wage Inequality and Skill Formation". We have received valuable comments from the participants at the International Economics Conference, Ankara, Turkey; Southeast Theory and International Economics Meetings, Houston; Eastern Economic Association Meetings, New York; Midwest International Economics Meetings, State College and at the Union College economics seminar. The standard disclaimer applies.
} 
increase in the relative employment of unskilled labor in the North and skilled labor in the South.

Putting these HO model predictions to test, economists have found little empirical support for the trade explanation. First, the observed increase in the relative prices of skilled-labor-intensive products in the North was not strong enough to generate large movements in relative wages. Second, the increase in wage inequality occurred simultaneously in the Northern and most of the Southern countries. Third, within each industry the relative employment of skilled labor has increased in both the North and South despite the rising relative cost of skilled labor. Based on these, along with other evidence on technological change, the current consensus appears to be favoring skill-biased technological change over trade as the major explanation behind the recent labor market developments. ${ }^{1}$

The wage inequality debate so far has paid relatively little attention to the role that foreign direct investment (FDI) and outsourcing activity can play in explaining the labor market developments. Moreover, only a few attempts have been made to investigate the wage trends in a unified North-South framework. This is surprising when one considers the fact that relative wage trends across the globe have been synchronous with a drastic increase in the level of FDI and international outsourcing activity. ${ }^{2}$ Furthermore, a number of empirical studies have found a strong correlation between outsourcing/FDI activity and relative wages. Feenstra and Hanson (1999) attribute $15 \%$ of the rise in US wage inequality to international outsourcing by US multinational firms. Using evidence from Mexico and Venezuela, Aitken, Harrison, and Lipsey (1996) show that increased foreign ownership in the host country raises the wages of skilled workers by more than those of unskilled workers. ${ }^{3}$

The theoretical models that investigate the relationship between FDI/outsourcing and wages mostly use static factor-endowment based trade models with no consideration of technological progress. In a widely cited paper Feenstra and Hanson (1997) construct such a model in which a single final good is produced from a continuum of intermediate inputs. In their model, a movement of capital from the North to the South shifts more intermediate goods production to the South. From the North's standpoint, this implies the loss of least skilled-intensive activities; from the South's standpoint, this implies the gain of more skilled-intensive activities. As a result, increased outsourcing raises the relative demand for skilled labor, increasing the skill premia in both the North and the South. ${ }^{4}$ In another static factor-endowment framework, Markusen and Venables $(1998,1999)$ study the impact of multinational firms on real wages in both the host and the source economies. They find that the real wage implications of multinationals depend on the initial conditions and factor endowments of both economies.

In this paper, we intend to construct a dynamic North-South model that explicitly incorporates the mechanics of innovation, outsourcing and imitation. We depart from Feenstra and Hanson (1997) on three accounts. First, we model international outsourcing as part of a product cycle framework in which outsourcing is triggered by technology transfer opportunities. Second, in our setting endogenous technological change generates continuous product quality improvements and leads to steady-state real wage growth. Third, we allow for substitutability between skilled and unskilled labor in manufacturing.

Our model is a variant of the standard North-South quality-ladders growth model of Grossman and Helpman (1991). We remove scale effects from the endogenous growth structure in the spirit of Dinopoulos and Thompson (2000). We incorporate outsourcing along the lines of Glass and Saggi (2001), and enrich their setting by adding 
two new layers. First, we allow for two types of labor-skilled and unskilled-to be employed in manufacturing. Second, we assume that production can shift to the South not only by outsourcing but also by imitation. In Glass and Saggi (2001) there is only one type of labor, and outsourcing is the only channel by which production shifts from the North to the South.

In our model, the global economy consists of a continuum of industries. In each industry Northern firms engage in R\&D to discover higher quality products. For each industry, location of production moves according to a product cycle mechanism that involves three phases: Northern, Outsourcing and Southern phase. In the Northern phase, a successful Northern innovator with the state-of-the-art technology manufactures its product by using Northern resources. Thus, production takes place exclusively in the North. In the Outsourcing phase, some degree of standardization is attained and the Northern leader shifts a certain portion of production to the South. Hence, production is fragmented between the North and the South. In the Southern phase, the state-of-the-art technology fully leaks to the South. Thus, production takes place exclusively in the South. Further innovation by a Northern firm reignites these product cycle dynamics.

We consider the effects of two exogenous events. The first is an increase in the fraction of production outsourced to the South. This event raises the relative wage in the North, while increasing the relative wage in the South if and only if production outsourced to the South is more skilled-labor intensive relative to local Southern production. The second is a rise in the probability of outsourcing success by the Northern leaders. This event raises the relative wage in the North, while increasing the relative wage in the South under the same if and only if condition, provided a certain assumption holds in equilibrium (see Proposition 2). ${ }^{5}$ Running numerical simulations of the model, we find that the larger the skill-intensity gap between outsourced and local production the larger the response of skill premia in both regions to increased outsourcing. Further, the simulations indicate that as the skill-intensity gap widens, the responsiveness of Southern skill premium rises more rapidly relative to that of Northern skill premium.

A comparison of these results to those of Feenstra and Hanson (1997) can be useful. Similar to Feenstra and Hanson (1997), we find that increased trade via outsourcing can lead to rising skill premia in both the North and the South. We also show that the extent of the skill-intensity gap can be the key in explaining the mixed trends in Southern wage inequality. This argument is somewhat in the spirit of Feenstra and Hanson (1997), but not explicitly demonstrated in their paper. We further depart from Feenstra and Hanson (1997) by arguing that increased outsourcing raises the Northern skill premium regardless of the North-South skill intensity gap in manufacturing. This is due to the presence of a Northern R\&D sector that exclusively employs skilled labor. In Feenstra and Hanson (1997), there is no R\&D sector, and outsourcing increases the Northern skill premium if and only if the North-South skill intensity gap in intermediate-goods production is positive.

In the paper, we also report the real wage effects of increased outsourcing. At the steady-state equilibrium, ongoing technological progress leads to continuous productquality improvements and stimulates real wage growth - in quality adjusted termsfor all types of labor. Hence, exogenous shocks can exert both a level and a growth effect on real wages. This growth effect provides a new layer of analysis, which, by construction, is absent in static models such as Feenstra and Hanson (1997). We find that an increase in the fraction of outsourced production raises the real wage growth rate for all types of labor in both regions. On the other hand, an increase in the probability 
of outsourcing success exerts an ambiguous growth effect. However, numerical simulations indicate that it also stimulates real wage growth under a wide range of reasonable parameters.

Lastly, it is worth mentioning that our model is not subject to the pitfalls of the $\mathrm{H}-\mathrm{O}$ setting. In our model, changes in relative wages do not necessarily operate through variations in the relative prices of manufactured goods. Further, rising skill premia in both the North and the South can be observed in the presence of increased trade stemming from more outsourcing. ${ }^{6}$

Section 2 describes the model and establishes the steady-state equilibrium. Section 3 provides a comparative steady-state analysis. Section 4 concludes. Proofs of existence and uniqueness of equilibrium, comparative steady-state results, and discussion of numerical simulations are relegated to Appendices (available at http://www1. union.edu/ senerm/ and also upon request).

\section{The Model}

The world economy consists of two countries, the North and the South indexed by $i \in$ $\{N, S\}$. The population size in country $i$ at time $t$ is $N^{i}(t)=N_{0}^{i} e^{n t}$, where $N_{0}^{i}$ denotes the initial level of population and $n>0$ stands for the population growth rate. In each country the labor force consists of skilled and unskilled workers. In country $i$, the population share of skilled labor is given by $h^{i}$, and that of unskilled labor is given by $\left(1-h^{i}\right)$. Given the fixed population shares, the stock of each type of labor grows at a rate of $n$.

\section{Household Behavior}

In each country, there exists a continuum of identical households whose measure is equal to one. Each household takes goods prices, factor prices, and the interest rate as given and maximizes its utility over an infinite horizon

$$
U^{i}=\int_{0}^{\infty} N_{0}^{i} e^{-(\rho-n) t} \log u^{i}(t) d t, \quad \text { for } i=N, S,
$$

where $\rho$ is the subjective discount rate, and $\log u^{i}(t)$ is the instantaneous utility of each household member defined as:

$$
\log u^{i}(t) \equiv \int_{0}^{1} \log \left[\sum_{j} \lambda^{j} x^{i}(j, \omega, t)\right] d \omega, \quad \text { for } i=N, S,
$$

where $x^{i}(j, \omega, t)$ is the quantity demanded of a product with quality $j$ in industry $\omega$ at time $t$. The size of quality improvements (the innovation size) is denoted by $\lambda>1$. Therefore, the total quality of a good after $j$ innovations is $\lambda^{j}$.

Each household allocates its per capita consumption expenditure $c^{i}(t)$ to maximize $u^{i}(t)$ given prices at time $t$. Note that all products within an industry are perfect substitutes; thus, households buy only the products with the lowest quality-adjusted prices. Products enter the utility function symmetrically; therefore, households spread their consumption expenditure evenly across goods. The resulting per capita product demand for each product line is $x^{i}(t)=c^{i}(t) / p_{m}$, where $p_{m}$ is the relevant market price for the product that has the lowest quality-adjusted price. 
Given the static demand behavior, the household's problem is simplified to maximizing

$$
\int_{0}^{\infty} N_{0}^{i} e^{-(\rho-n) t} \log c^{i}(t) d t, \quad \text { for } i=N, S,
$$

subject to the budget constraint $\dot{A}^{i}(t)=W^{i}(t)+r(t) A^{i}(t)-c^{i}(t) N^{i}(t)$, where $A^{i}(t)$ denotes the financial assets owned by the household, $W^{i}(t)$ is the family's expected wage income and $r(t)$ is the instantaneous rate of return. ${ }^{7}$ The solution to this optimization gives the standard differential equation

$$
\frac{\dot{c}^{i}(t)}{c^{i}(t)}=r^{i}(t)-\rho, \quad \text { for } i=N, S .
$$

At the steady-state equilibrium, $c^{i}$ remains fixed; thus, the market interest rate $r^{i}(t)$ is equal to the subjective discount rate $\rho$. In this paper, we will focus on the balancedgrowth path of the economy and hence we will later drop the time index for the variables that remain constant.

\section{Product Cycle Dynamics}

The global economy consists of a continuum of structurally-identical industries indexed by $\omega \in[0,1]$. At any point in time, each industry can be classified as a Northern industry, an Outsourcing industry, or as a Southern industry. For each industry the transition from one industry structure to another is governed by a stochastic Poisson process. We explain this transition mechanism and the dynamics of the product cycle framework below.

In the North, entrepreneur firms participate in R\&D races aimed at innovating higher quality products. The probability of innovation success in industry $\omega$ over a small time interval $d t$ equals $t(\omega, t) d t$ and is endogenously determined. Successful Northern entrepreneurs can exercise temporary monopoly power in the global market and immediately start manufacturing by hiring Northern workers. Industries in which Northern firms manufacture final goods by using Northern resources are called Northern industries.

While producing in the North, with exogenous probability $f(\omega, t) d t$, a Northern monopolist in industry $\omega$ can successfully outsource a certain portion of manufacturing to the South. ${ }^{8}$ In equilibrium, Southern manufacturing costs are sufficiently low such that the value of an Outsourcing firm is larger than that of a Northern firm. Therefore, Northern leaders have an incentive to exploit outsourcing opportunities whenever they arise. Industries in which Northern quality leaders split production between North and South are called Outsourcing industries.

When Northern firms engage in outsourcing, Southern firms have direct contact with the state-of-the-art production technologies. With exogenous probability $\delta(\omega, t) d t$, Southern firms in industry $\omega$ can fully acquire the state-of-the-art technology and drive the Northern firm out of the global market. We assume that when technology leaks to the South it becomes available to all Southern firms. Hence, Southern production takes place in a perfectly competitive setting. Industries in which Southern firms perform the entire manufacturing are called Southern industries. When an industry is classified as a Southern industry, it becomes the target of the R\&D efforts of Northern entrepreneurs. Each success by a Northern R\&D firm reignites the product cycle mechanism described above. ${ }^{9}$ 


\section{Stock Market Valuations}

There exists a stock market that channels household savings to firms. Let $j=N, F, S$ represent the industry index for Northern, Outsourcing and Southern industries, respectively. Denote with $v_{j}(\omega, t)$ the stock market value and $\pi_{j}(\omega, t)$ the profit flow of a producer firm operating in industry $j$ for $j=N, F, S$.

Consider first the valuation of a Northern firm $v_{N}(\omega, t)$. Over a time interval $d t$, the stockholders of this firm receive $\pi_{N}(\omega, t)$ in the form of dividend payments. With probability $f(\omega, t) d t$, the Northern firm can become an Outsourcing firm. In this event, the stockholders realize a gain in value of $v_{F}(\omega, t)-v_{N}(\omega, t)>0$. With probability $(1-f(\omega$, $t) d t$, the Northern firm's production remains in the North, and the stockholders experience a change in value given by $\dot{v}_{N}(\omega, t)$. The absence of any arbitrage opportunities in the stock market implies that the expected rate of return from holding a stock issued by a Northern firm must be equal to the risk-free market interest rate $r(t)$. This implies (taking limits as $d t \rightarrow 0$ ):

$$
v_{N}(\omega, t)=\frac{\pi_{N}(\omega, t)+f(\omega, t) v_{F}(\omega, t)}{r(t)+f(\omega, t)-\left(\dot{v}_{N}(\omega, t) / v_{N}(\omega, t)\right)} .
$$

Consider now the valuation of an Outsourcing firm $v_{F}(\omega, t)$. Over a time interval $d t$, the stockholders of this firm receive $\pi_{F}(\omega, t)$ in the form of dividend payments. With probability $\delta(\omega, t) d t$, the technology of the Outsourcing firm can fully leak to the South. In this event, the stockholders realize a loss in value of $v_{F}(\omega, t)$. With probability $(1-\delta(\omega, t) d t)$, the Outsourcing firm maintains its leadership position, and the stockholders experience a change in value given by $\dot{v}_{F}(\omega, t)$. Again, the absence of arbitrage opportunities implies (taking limits as $d t \rightarrow 0$ ):

$$
v_{F}(\omega, t)=\frac{\pi_{F}(\omega, t)}{r(t)+\delta(\omega, t)-\left(\dot{v}_{F}(\omega, t) / v_{F}(\omega, t)\right)} .
$$

Finally, consider the valuation of a Southern firm $v_{S}(\omega, t)$. Since Southern production takes place in a perfectly competitive setting, it follows that $\pi_{S}(\omega, t)=0$ and thus $v_{S}(\omega, t)=0$.

\section{$R \& D$ Races}

Northern firms undertake $R \& D$ to participate in sequential $R \& D$ races. $R \& D$ is a costly activity that involves uncertainty. A Northern firm $j$ which undertakes R\&D intensity $l_{j}$ for a time period $d t$ innovates the next generation product with probability $l_{j} d t$. In this event, the entrepreneur realizes the value of a successful innovator $v_{N}(t)$. To conduct R\&D, Northern entrepreneurs hire skilled labor. Let $w_{H}^{i}$ and $w_{L}^{i}$ represent the wage rate of skilled and unskilled labor for $i=N, S$, respectively. The cost of undertaking R\&D intensity $l_{j}$ for a time period $d t$ equals $w_{H}^{N} a_{l} X_{l}(t) l_{j} d t$, where $a_{\imath} X_{l}(t)$ represents the labor requirement per $\mathrm{R} \& \mathrm{D}$ intensity. The term $X_{l}(t)$ is a measure of $\mathrm{R} \& \mathrm{D}$ difficulty, which is introduced to remove the scale effects from the model. We specify $X_{l}(t)$ as

$$
X_{t}(t)=k_{l} N^{N}(t)
$$

where $k_{l}$ is a positive constant. ${ }^{10}$ Free entry into $\mathrm{R} \& \mathrm{D}$ races implies the following zero profit condition: 


$$
v_{N}(t)=w_{H}^{N} a_{\imath} X_{\imath}(t) .
$$

We assume that returns to $R \& D$ activity are distributed independently across firms and structurally-identical, industries; thus, the innovation rate in industry $\omega$ is $t(\omega, t)=\Sigma_{j} l_{j}=t$.

\section{Manufacturing Technology and Product Markets}

In Northern industries, the production function for final-goods manufacturing is represented by a standard production function $F_{N}\left(H_{N}, L_{N}\right)$, where $H_{N}$ and $L_{N}$ stand for skilled and unskilled employment, respectively. By a standard production, we mean a concave and constant returns to scale production function with positive marginal products. For such functions, unit labor requirements in production can be expressed as a function of the relative wage. Let $w^{i}=w_{H}^{i} / w_{L}^{i}$ represent the relative wage of skilled labor for $i=N, S$. Let $a_{H N}\left(w^{N}\right)$ and $a_{L N}\left(w^{N}\right)$ stand for skilled and unskilled unit labor requirements in Northern production, where $\partial a_{H N}\left(w^{N}\right) / \partial w^{N}<0$ and $\partial a_{L N}\left(w^{N}\right) / \partial w^{N}>0 .{ }^{11}$ Thus, the unit cost of production in a Northern industry is:

$$
A C_{N}=a_{H N}\left(w^{N}\right) w_{H}^{N}+a_{L N}\left(w^{N}\right) w_{L}^{N} .
$$

In Outsourcing industries, production is split into two stages: basic and advanced production. To produce one unit of final good, an outsourcing firm must combine $\alpha$ units of basic production with $(1-\alpha)$ units of advanced production. One can view this as a Leontief production technology whereby two different types of intermediate products (basic and advanced) are combined at fixed proportions $(\alpha$ and $1-\alpha)$ to produce one unit of final output. Alternatively, one can visualize this as a fragmented production scheme whereby advanced production involves the manufacturing of sophisticated intermediate inputs and basic production involves the assembly of final goods by using these intermediate inputs. We assume that basic and advanced production require both skilled and unskilled labor. We consider standard production functions that allow for substitutability between inputs; consequently, unit labor requirements respond to variations in factor prices. Compared to Glass and Saggi (2001), this is a more flexible production scheme. In Glass and Saggi (2001), there is only one type of labor and one unit of labor is required to produce one unit of final good. More specifically, an outsourcing firm can fragment the production process by employing $1-\alpha$ units of Northern labor and $\alpha$ units of Southern labor. Hence, in their model unit labor requirements do not respond to factor prices in either country.

Basic production can be outsourced to the South, whereas advanced production remains in the North. For advanced production, it is natural to assume that Northern production technology $F_{N}(\cdot)$ applies; thus, the unit labor requirements for skilled and unskilled labor are $a_{H N}\left(w^{N}\right)$ and $a_{L N}\left(w^{N}\right)$. For basic production, the relevant production function is $F_{F}(\cdot)$. Since basic production uses Southern factors, the unit labor requirements for skilled and unskilled labor are now functions of the Southern relative wage: $a_{H F}\left(w^{S}\right)$ and $a_{L F}\left(w^{S}\right)$, where $\partial a_{H F}\left(w^{S}\right) / \partial w^{S}<0$ and $\partial a_{L F}\left(w^{S}\right) / \partial w^{S}>0$. The unit cost of production in an Outsourcing industry is then the sum of basic and advanced production costs:

$$
A C_{F}=(1-\alpha)\left[a_{H N}\left(w^{N}\right) w_{H}^{N}+a_{L N}\left(w^{N}\right) w_{L}^{N}\right]+\alpha\left[a_{H F}\left(w^{S}\right) w_{H}^{S}+a_{L F}\left(w^{S}\right) w_{L}^{S}\right] .
$$

In Southern industries, the relevant production function is $F_{S}(\cdot)$. Since Southern producers face the Southern wages, the unit labor requirements for skilled and unskilled labor are $a_{H S}\left(w^{S}\right)$ and $a_{L S}\left(w^{S}\right)$, where $\partial a_{H S}\left(w^{S}\right) / \partial w^{S}<0$ and $\partial a_{L S}\left(w^{S}\right) / \partial w^{S}>0$. The unit cost of production in a Southern industry is 


$$
A C_{S}=a_{H S}\left(w^{S}\right) w_{H}^{S}+a_{L S}\left(w^{S}\right) w_{L}^{S}=1,
$$

which is used as the numeraire and normalized to one.

We are now in a position to calculate the profit flows of producers in each industry. We restrict attention to steady-state outcomes where the ranking of unit costs are $\lambda>$ $A C_{N}>A C_{F}>A C_{S}=1$. In the product markets, firms compete in prices under free-trade conditions. In each Northern industry, a Northern quality leader competes with a fringe of Southern followers. The Northern firm has access to the technology of producing the state-of-the-art quality product, whereas the Southern followers have access to the technology of producing the previous generation product. ${ }^{12}$ The incremental quality difference between the Northern product and the Southern product is $\lambda$. If the Southern followers charge a price equal to marginal cost, the numeraire, the Northern leader can capture the entire market by charging $\lambda-\varepsilon$. Thus, by engaging in limit pricing, the Northern firm forces the Southern followers out of the global market. The Southern followers cannot do better than break even. The profit flow of a Northern firm is

$$
\pi_{N}(t)=E(t) \frac{\lambda-A C_{N}}{\lambda},
$$

where $E(t)=c^{N} N^{N}(t)+c^{S} N^{S}(t)$ stands for the level of global consumption expenditure.

In each Outsourcing industry, a Northern quality leader engaged in outsourcing competes with Southern followers who can produce the previous generation product. The Outsourcing firm also engages in limit pricing and charges a price of $\lambda$, sustaining monopoly power in the global market. The Southern followers cannot do better than break even. The profit flow of an Outsourcing firm is ${ }^{13}$

$$
\pi_{F}(t)=E(t) \frac{\lambda-A C_{F}}{\lambda} .
$$

In Southern industries, competition takes place among a fringe of Southern firms and the Outsourcing firm. All have access to the state-of-the-art technology. Price competition among Southern firms drives prices down to marginal cost one. The Outsourcing firm cannot charge below $A C_{F}>1$ and exit the market. As a result, Southern firms supply the market, earning zero profits $\pi_{S}(t)=0$.

\section{Industry Flows and Labor Markets}

Let $n_{N}, n_{F}$ and $n_{S}$ represent the fraction of Northern, Outsourcing, and Southern industries, respectively. At the steady-state equilibrium, industry shares remain constant; thus, the flows in and out of each industry must be exactly balanced. First, consider the Northern industries. Northern entrepreneurs capture production from Southern industries at a rate of $i n_{S}$, whereas Northern firms transform into Outsourcing firms at a rate of $f n_{N}$. Constancy of $n_{N}$ implies:

$$
i n_{S}=f n_{N} .
$$

Next, consider the Outsourcing industries. The inflow into the Outsourcing industry pool is $f n_{N}$, whereas the outflow equals the aggregate rate of imitation success in the South $\delta n_{F}$. Constancy of $n_{F}$ implies:

$$
f n_{N}=\delta n_{F} .
$$

Since the measure of industries equals one, $n_{N}+n_{F}+n_{S}=1$, it follows that $n_{S}$ is constant when the above two conditions hold. 
Labor market equilibrium requires labor supply be equal to labor demand for each type of labor for $i=N, S$. First, we consider the Northern labor markets. In the North, demand for skilled labor comes from R\&D and manufacturing. For each industry targeted by Northern entrepreneurs, demand for R\&D workers is $\imath_{l} X_{l}$. Since Northern industries target only Southern industries, total demand for skilled workers coming from $\mathrm{R} \& \mathrm{D}$ is $n_{S} l a_{\imath} X_{l}$. In each Northern industry, demand for skilled labor to be employed in manufacturing is $a_{H N}\left(w^{N}\right)(E / \lambda)$ and in each Outsourcing industry such demand equals $(1-\alpha) a_{H N}\left(w^{N}\right)(E / \lambda)$. Hence total demand for skilled workers coming from manufacturing is $n_{N} a_{H N}\left(w^{N}\right)(E / \lambda)+n_{F}(1-\alpha) a_{H N}\left(w^{N}\right)(E / \lambda)$. Skilled labor market equilibrium in the North implies:

$$
h^{N} N^{N}=n_{S} l a_{\imath} X_{\imath}+n_{N} a_{H N}\left(w^{N}\right)(E / \lambda)+n_{F}(1-\alpha) a_{H N}\left(w^{N}\right)(E / \lambda) .
$$

In the North, demand for unskilled labor comes exclusively from manufacturing. In each Northern industry, demand for unskilled labor is $a_{L N}\left(w^{N}\right)(E / \lambda)$, and in each Outsourcing industry such demand equals $(1-\alpha) a_{L N}\left(w^{N}\right)(E / \lambda)$. Hence, total demand for unskilled workers is $n_{N} a_{L N}\left(w^{N}\right)(E / \lambda)+n_{F}(1-\alpha) a_{L N}\left(w^{N}\right)(E / \lambda)$. Unskilled labor market equilibrium in the North implies:

$$
\left(1-h^{N}\right) N^{N}=n_{N} a_{L N}\left(w^{N}\right)(E / \lambda)+n_{F}(1-\alpha) a_{L N}\left(w^{N}\right)(E / \lambda) .
$$

Next, we examine the Southern labor markets. In the South, manufacturing is the only activity that generates labor demand. In each Southern industry, demand for skilled labor is $a_{H S}\left(w^{S}\right)(E / 1)$. In each Outsourcing industry, such demand equals $\alpha a_{H F}\left(w^{S}\right)(E / \lambda)$. Hence, total demand for skilled workers is $n_{S} a_{H S}\left(w^{S}\right) E+$ $n_{F} \alpha a_{H F}\left(w^{S}\right)(E / \lambda)$. Skilled labor market equilibrium in the South implies:

$$
h^{S} N^{S}=n_{S} a_{H S}\left(w^{S}\right) E+n_{F} \alpha a_{H F}\left(w^{S}\right)(E / \lambda) .
$$

In each Southern industry, the demand for unskilled workers is $a_{L S}\left(w^{S}\right)(E / 1)$ and in each Outsourcing industry such demand equals $\alpha a_{L F}\left(w^{S}\right)(E / \lambda)$. Hence, total demand for unskilled workers is $n_{S} a_{L S}\left(w^{S}\right) E+n_{F} \alpha a_{L S}\left(w^{S}\right)(E / \lambda)$. Unskilled labor market equilibrium in the South implies:

$$
\left(1-h^{S}\right) N^{S}=n_{S} a_{L S}\left(w^{S}\right) E+n_{F} \alpha a_{L F}\left(w^{S}\right)(E / \lambda) .
$$

\section{Steady-State Equilibrium}

At the steady state equilibrium $c^{i}, w_{H}^{i}, w_{L}^{i}, \imath, n_{N}, n_{F}$, and $n_{S}$ remain constant, whereas $X(t), E(t), v_{N}(t)$ and $v_{F}(t)$ grow at the rate of population growth $n$. We characterize the equilibrium in a step wise fashion. We first obtain expressions for industry shares in terms of innovation, imitation, and outsourcing rates, $\imath, \delta$ and $f$, respectively. Using (14) and (15), and $n_{N}+n_{F}+n_{S}=1$, we derive:

$$
n_{N}=\frac{\imath \delta}{f \delta+\imath(\delta+f)}, \quad n_{F}=\frac{\imath f}{f \delta+\imath(\delta+f)}, \quad n_{S}=\frac{f \delta}{f \delta+\imath(\delta+f)} .
$$

Next, we substitute the industry shares from (20) into (16) and (17). Taking the ratio of the resulting expressions and solving for $E$ using (7) yields:

$$
E\left(w^{N} ; \alpha, f\right)=\lambda k N^{N} a_{\imath}\left(\left(\frac{1}{f}+\frac{1-\alpha}{\delta}\right)\left(\frac{a_{L N}\left(w^{N}\right) h^{N}}{1-h^{N}}-a_{H N}\left(w^{N}\right)\right)\right)^{-1},
$$


where $\partial E / \partial w^{N}<0, \partial E / \partial \alpha>0$ and $\partial E / \partial f>0$. Equation (21) captures the relative supply and demand relationships between skilled and unskilled labor in the North. To see the intuition behind $\partial E / \partial w^{N}<0$, consider an increase in global spending $E$, holding $w^{N}$ constant. Such a change raises the level of manufacturing activity relative to R\&D. Since manufacturing is unskilled labor intensive relative to $R \& D$, this boosts the relative demand for unskilled labor and leads to a decline in the Northern relative wage $w^{N}$.

We now substitute $E\left(w^{N}, \alpha, f\right)$ from (21) into (17) and solve for $\imath$. This yields:

$$
\imath\left(w^{N} ; \alpha, f\right)=\left(\frac{a_{l} k}{h^{N}-\left(1-h^{N}\right)\left(a_{H N}\left(w^{N}\right) / a_{L N}\left(w^{N}\right)\right)}-\frac{1}{f}-\frac{1}{\delta}\right)^{-1},
$$

where $\partial \imath / \partial w^{N}>0, \partial \imath / \partial \alpha=0$ and $\partial \imath / \partial f<0$. Equation (22) essentially captures the Northern unskilled labor market equilibrium condition. To see the intuition behind $\partial \imath / \partial w^{N}>0$, consider an increase in the Northern relative wage $w^{N}$, holding $\imath$ constant. Such a change has two opposing effects. First, a higher $w^{N}$ reduces $E$ by equation (21), depressing the demand for unskilled labor. Second, a higher $w^{N}$ reduces the relative cost of employing unskilled labor and increases the demand for unskilled labor. Equation (23) implies that the net impact is a fall in the demand for unskilled labor. To restore equilibrium, there must be an increase in the fraction of Northern and Outsourcing industries via an increase in $\imath$ [see (20)].

Next, we substitute $E$ from (21) and $\imath$ from (22) into Southern labor market conditions. This will generate two equations in terms of $w^{N}$ and $w^{S}$ and determine the equilibrium levels of relative wages.

First, substituting for $E$ and $\imath$ in the Southern skilled labor market equation (18) gives:

$$
\frac{\left(1-h^{N}\right)\left[\alpha a_{H F}\left(w^{S}\right)+\lambda a_{H S}\left(w^{S}\right)\left(\delta / \imath\left(w^{N}, \alpha, f\right)\right)\right]}{a_{L N}\left(w^{N}\right)[(\delta / f)+1-\alpha]}=h^{S} \eta^{S}, \quad \boldsymbol{S H}
$$

where $\eta^{S}=N^{S} / N^{N}$. Equation (23) establishes a negative relationship between $w^{N}$ and $w^{S}$. To see the intuition, consider an increase in $w^{N}$, holding $w^{S}$ constant. By (21) and (22), an increase in $w^{N}$ reduces $E$ and increases $t$. Through equation (20), the higher $\imath$ increases $n_{N}$ and $n_{F}$, and reduces $n_{S}$. In the Outsourcing sector, the reduction in global spending $E$ decreases the level of production per industry, whereas the increase in $n_{F}$ raises the measure of Outsourcing industries, the combined effect pointing to a fall in manufacturing activity. ${ }^{14}$ On the other hand, in the Southern sector, the lower levels of both $E$ and $n_{S}$ unambiguously reduce manufacturing activity. To sum up, a higher $w^{N}$ leads to a contraction in aggregate Southern manufacturing. In the Southern skilled labor market this depresses the demand for workers, leading to a decrease in the Southern relative wage $w^{S}$.

Second, substituting for $E$ and $\imath$ in the Southern unskilled labor market equation (19) yields:

$$
\frac{\left(1-h^{N}\right)\left[\alpha a_{L F}\left(w^{S}\right)+\lambda a_{L S}\left(w^{S}\right)\left(\delta / \imath\left(w^{N}, \alpha, f\right)\right)\right]}{a_{L N}\left(w^{N}\right)[(\delta / f)+1-\alpha]}=\left(1-h^{S}\right) \eta^{S}, \quad \boldsymbol{S} \boldsymbol{L} .
$$

Equation (24) establishes a positive relationship between $w^{N}$ and $w^{S}$. For a given $w^{S}$, a higher $w^{N}$ reduces $E$ and $n_{S}$, and increases $n_{N}$ and $n_{F}$. As before, in the Outsourcing sector, the combined effect of a fall in $E$ and the rise in $n_{F}$ implies a reduction in manufacturing activity. On the other hand, in the Southern sector, the lower levels of $E$ and $n_{S}$ both imply a fall in manufacturing activity. The resulting contraction in aggre- 


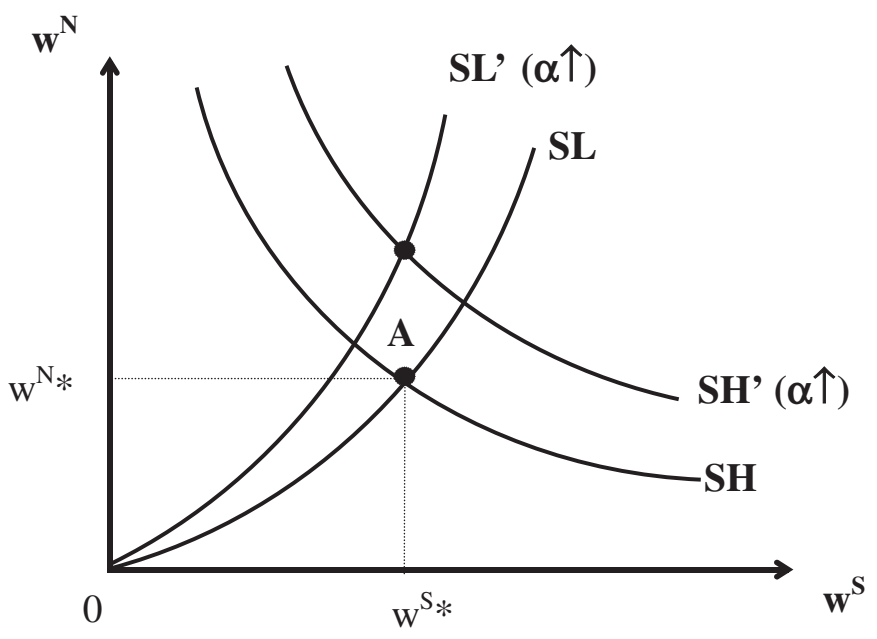

Figure 1. Relative Wages in the North and the South

gate Southern manufacturing depresses the demand for unskilled workers, leading to an increase in the Southern relative wage $w^{S}$.

Figure 1 illustrates the steady-state equilibrium levels of relative wages $w^{S}$ and $w^{N}$ by the intersection of the SH and SL curves at point A. We use "*" to refer to equilibrium levels of endogenous variables. Substituting $\left(w^{N}\right) *$ into equations (21) and (22) yields $E^{*}$ and $\imath^{*}$. Substituting $\imath^{*}$ into (20) yields $n_{N}^{*}, n_{F}^{*}$ and $n_{S}{ }^{*}$.

To find the equilibrium levels of skilled and unskilled Southern wages in terms of the numeraire, we first plot (11) on $\left(w_{H}^{S}, w_{L}^{S}\right)$ space. Equation (11) implies a negative relationship between $w_{H}^{S}$ and $w_{L}^{S}$, which is shown by the $A C_{S}$ curve in Figure 2a. The intuition is that a higher $w_{L}^{S}$ raises Southern manufacturing costs, and for (11) to hold, $w_{L}^{S}$ must fall. Combining this relationship with $\left(w^{S}\right)^{*}=w_{H}^{S} / w_{L}^{S}$, we determine the equilibrium levels $\left(w_{H}^{S}\right) *$ and $\left(w_{L}^{S}\right) *$ as illustrated by point $\mathrm{A}$ in Figure $2 \mathrm{a}$.

To determine the equilibrium levels of skilled and unskilled Northern wages, we first rewrite the free-entry in $\mathrm{R} \& \mathrm{D}$ condition (8). Substituting $v_{F}$ from (6) into (5), and then substituting the resulting expression for $v_{N}$ into (8) using (7), (12) and (13) yields:

$$
w_{H}^{N} a_{\imath} k N^{N}(\rho+f-n)=\frac{E(\cdot)}{\lambda}\left[\left(\lambda-A C_{N}\right)+f \frac{\left(\lambda-A C_{F}\right)}{(\rho+\delta-n)}\right], \quad \boldsymbol{F E}
$$

where $E, A C_{N}$ and $A C_{F}$ are given by (21), (9) and (10), respectively. Given ( $\left.w^{N}\right)^{*}$, equation (25) implies an inverse relationship between $w_{H}^{N}$ and $w_{L}^{N}$ as shown by the FE curve in Figure 2b. A higher $w_{H}^{N}$ increases both R\&D and manufacturing costs; to maintain the zero-profit condition in $\mathrm{R} \& \mathrm{D}$, there must be a decrease in $w_{L}^{N}$. Combining this relationship with $\left(w^{N}\right)^{*}=w_{H}^{N} / w_{L}^{N}$, we determine the equilibrium levels $\left(w_{H}^{N}\right)^{*}$ and $\left(w_{L}^{N}\right)^{*}$ as illustrated by point $\mathrm{A}$ in Figure $2 \mathrm{~b}$.

To complete the characterization of steady-state, we define three additional variables: $\chi$ as the extent of outsourcing, $I$ as the aggregate intensity of innovation, and $g$ as the rate of real wage growth. Since Outsourcing firms whose measure is $n_{F}$ outsource a portion $\alpha$ of their production, $\chi=\alpha n_{F}$. On the other hand, since Northern firms target their R\&D efforts at Southern industries whose measure is $n_{S}, I=\imath n_{S}$. At the steadystate equilibrium wage levels are fixed in terms of the numeraire; however, due to ongoing technological progress aimed at quality improvements, real wages in 


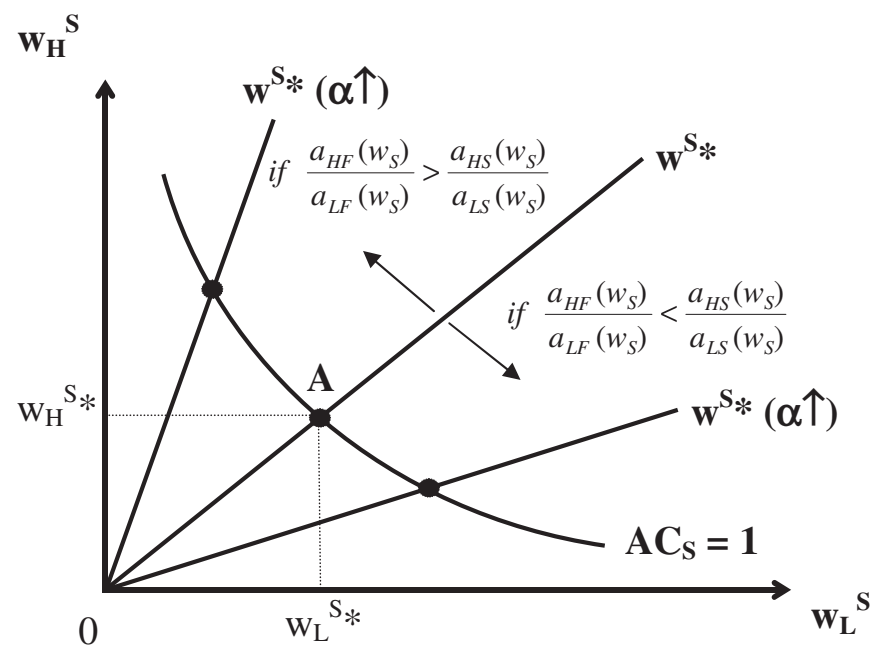

Figure 2a. Southern Wages (Levels)

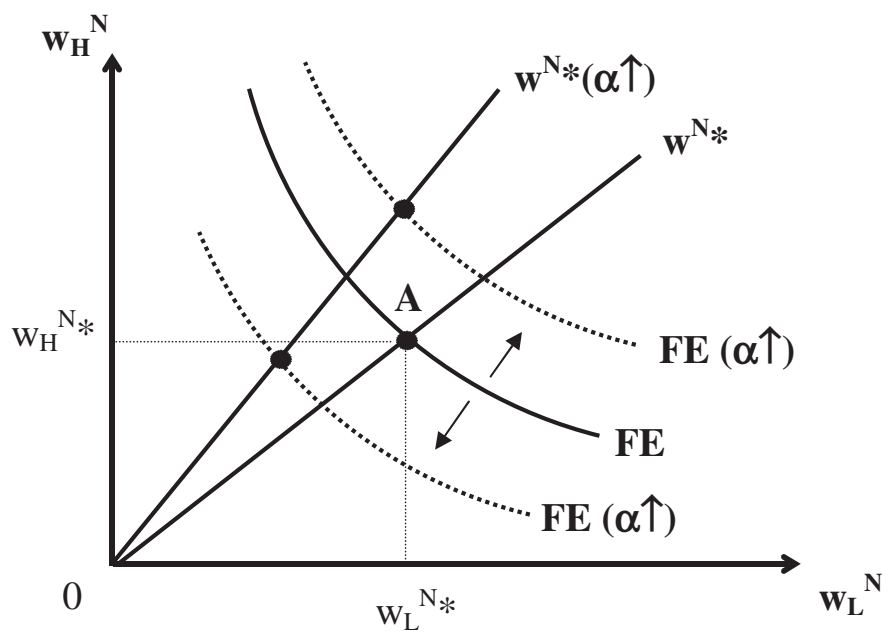

Figure 2b. Northern Wages (Levels)

quality-adjusted terms grow over time. More specifically, the quality-adjusted consumption price index falls at the rate of $I \ln \lambda$; hence, the rate of real wage growth for both types of labor equals $g=I \ln \lambda \cdot{ }^{15}$ Observe that due to free trade in final goods this is a common real wage growth rate that applies in both countries.

\section{Comparative Steady-State Analysis}

Proposition 1. An increase in the fraction of production outsourced to the South $\alpha$

a. raises the relative wage of skilled labor in the North $w^{N}$,

b. raises the relative wage of skilled labor in the South $w^{S}$ if and only if production outsourced to the South is more skilled labor intensive relative to local production in the South, that is $a_{H F}\left(w^{S}\right) / a_{L F}\left(w^{S}\right)>a_{H S}\left(w^{S}\right) / a_{L S}\left(w^{S}\right)$, 
c. increases the extent of outsourcing $\chi$,

$d$. raises the aggregate intensity of innovation I and thus the real wage growth rate $g$.

To see the intuition, consider first the impact on Southern labor markets using the $\mathrm{SH}$ and SL equations. For a given $w^{N}$, an increase in $\alpha$ raises the level of Southern production via two channels. First, as Northern firms outsource more production to the South, the level of Southern production directly increases. Second, the shift of manufacturing from the North to the South reduces the relative demand for unskilled labor in the North. Restoring Northern labor market equilibrium requires an increase in global spending $E$; thus, the level of Southern production indirectly increases.

We can now analyze the relative wage effects with the help of Figure 1 . The expansion in Southern production raises the demand for both skilled and unskilled Southern workers. In the skilled labor market, for a given $w^{N}$, the increased demand for skilled labor puts upward pressure on the relative wage of skilled labor $w^{S}$; thus, the SH curve shifts to the right. On the other hand, in the unskilled labor market, for a given $w^{N}$, the increased demand for unskilled labor puts downward pressure on $w^{S}$; thus, the SL curve shifts to the left. Consequently, we observe two competing effects on the Southern skill premium. In the Appendix, we show that the Southern relative wage $w^{S}$ increases if and only if production technology outsourced by the North is more skilled labor intensive relative to local Southern production technology.

With SH shifting right and SL shifting left, Figure 1 shows that the relative wage in the North $w^{N}$ unambiguously increases. To see the intuition, consider an increase in $\alpha$, now holding $w^{S}$ constant. As noted above, a higher $\alpha$ raises the demand for both skilled and unskilled labor in the South. For a given $w^{S}$, restoring equilibrium for both $\mathrm{SH}$ and SL equations requires an increase in $w^{N}$. This is because a higher $w^{N}$ reduces $E$ and raises $\imath$ (see (21) and (22)). The decline in global spending $E$ and the total measure of Southern and Outsourcing industries $n_{S}+n_{F}$ (triggered by the fall in $\imath$ ) eliminates the excess demand in both skilled and unskilled labor markets of the South.

To investigate the change in the rate of innovation $l$, we focus on (22). Given that a higher $\alpha$ raises $w_{N}$ and that $w_{N}$ and $t$ are positively related by (22), at the new equilibrium $\imath$ attains a higher level. ${ }^{16}$ With $\imath$ increasing, it follows from (20) that the measure of Northern and Outsourcing industries $n_{N}$ and $n_{F}$ increase, whereas the measure of Southern industries $n_{S}$ decreases. With $\alpha$ and $n_{F}$ both increasing, the extent of outsourcing $\chi=\alpha n_{F}$ increases as well. With $n_{N}$ increasing and $f$ being exogenous, equation (14) implies that the aggregate intensity of innovation $I=t n_{S}$ increases. Consequently, a rise in $\alpha$ leads to an increase in $g=I \ln \lambda$ and therefore stimulates more rapid growth in real wages.

To analyze the changes in wage levels, we utilize Figures $2 \mathrm{a}$ and $2 \mathrm{~b}$. We first focus on Figure 2a, which determines Southern wage levels. It follows from Proposition 1 that a higher $\alpha$ shifts the WS curve up if and only $a_{H F}\left(w^{S}\right) / a_{L F}\left(w^{S}\right)>a_{H S}\left(w^{S}\right) / a_{L S}\left(w^{S}\right)$. Hence, changes in Southern wage levels depend on the relative skill intensity between outsourcing and Southern production. However, from Figure $2 \mathrm{a}$ we can conclude that $w_{H}^{S}$ and $w_{L}^{S}$ always move in opposite directions. More specifically, if the wage gap between skilled and unskilled labor increases (decreases), the wage of skilled labor goes up (down) and that of unskilled labor goes down (up). Next, we focus on Figure $2 \mathrm{~b}$, which determines Northern wage levels. It follows from Proposition 1 that a higher $\alpha$ unambiguously shifts the WN curve up by raising $w_{N}$. On the other hand, it exerts multiple competing effects on the FE curve. First, an increase in $\alpha$ raises R\&D profitability by allowing Northern firms to exploit more low-cost manufacturing opportunities in the South (captured by the reduction in $A C_{F}$ ). Second, an increase in $\alpha$ 
causes ambiguous changes in Southern wages $w_{L}^{S}$ and $w_{H}^{S}$, as well as in global spending $E$; thus, the impact on $\mathrm{R} \& \mathrm{D}$ profitability via these channels remains ambiguous, implying that the FE curve may shift up or down. ${ }^{17}$ Consequently, the qualitative changes in Northern wages $w_{L}^{N}$ and $w_{H}^{N}$ depend on the parameters of the model.

\section{Proposition 2. An increase in the probability of outsourcing success $f$}

a. raises $w^{N}$,

b. under the assumption $A_{f}\left(\partial \mathrm{l} / \partial w_{N}\right)>A_{w N} \partial \mathrm{v} / \partial f$ where $A=\left(1-h^{N}\right) /[[(\delta / f)+(1-$ $\left.\alpha)] a_{L N}\left(w^{N}\right)\right]$, raises $w^{S}$ if and only if $a_{H F}\left(w^{S}\right) / a_{L F}\left(w^{S}\right)>a_{H S}\left(w^{S}\right) / a_{L S}\left(w^{S}\right)$,

c. has an ambiguous effect on $\chi$,

d. has an ambiguous effect on I and thus $g$.

Consider first the impact on SH and SL using Figure 1. An increase in $f$ leads to more jobs moving from the North to the South and thereby raises the demand for Southern labor. ${ }^{18}$ In the Southern skilled labor market, for a given $w^{N}$ this raises the skill premium $w^{S}$ and shifts the SH curve to the right. In the Southern unskilled labor market, for a given $w^{N}$ this reduces $w^{S}$ and shifts the SL curve to the left. Consequently, we observe two competing effects on the Southern relative wage $w^{S}$-as in the case of an increase in $\alpha$. In the Appendix, we show that under the assumption $A_{f}\left(\partial \imath / \partial w^{N}\right)>A_{w N} \partial \imath / \partial f$, the Southern skill premium $w^{S}$ increases if and only if $a_{H F}\left(w^{S}\right) / a_{L F}\left(w^{S}\right)>a_{H S}\left(w^{S}\right) / a_{L S}\left(w^{S}\right)$. With SH shifting right and SL shifting left, Figure 1 shows that the relative wage in the North $w^{N}$ unambiguously increases. Equation (22) implies that a higher $f$ triggers two competing effects on $t$ : a direct positive influence, and an indirect negative influence through an increase in $w_{N} \cdot{ }^{19}$ The net impact depends on the parameters of the model. With $f$ increasing and the change in $r$ ambiguous, the net impact on industry measures also remains indeterminate and hence the variations in $\chi, I$ and $g$. In an attempt to resolve the ambiguities, we ran numerical simulations of the model. Under a wide range of parameter values, the following regularities emerged. First, the assumption $A_{f}\left(\partial v / \partial w_{N}\right)>A_{w N} \partial t / \partial f$ holds and thus the if and only if condition is generally valid. Second, an increase in $f$ raises $\chi, I$ and $g$.

We now analyze the changes in wage levels. We begin with Southern wage levels using Figure 2a. It follows from Proposition 2 that under the assumption $A_{f}\left(\partial v / \partial w^{N}\right)>$ $A_{w N} \partial \imath / \partial f$, a higher $f$ shifts the WS curve up if and only $a_{H F}\left(w^{S}\right) / a_{L F}\left(w^{S}\right)>a_{H S}\left(w^{S}\right) / a_{L S}\left(w^{S}\right)$. Despite the ambiguity, we can conclude, as before, that $w_{L}^{S}$ and $w_{H}^{S}$ move in opposite directions under all possible cases. Next, we analyze Northern wage levels using Figure 2b. It follows from Proposition 1 that a higher $f$ shifts the WN curve up, but it generates multiple competing effects on the FE curve. First, an increase in $f$ exerts a direct positive influence on R\&D profitability by raising the probability of outsourcing success. Second, as noted above, an increase in $f$ generates ambiguous changes in Southern wages $w_{L}^{S}$ and $w_{H}^{S}$ as well as in $E$; thus the impact on R\&D profitability via these channels remains ambiguous. ${ }^{20}$ Consequently, the FE curve may shift up or down; thus, changes in $w_{L}^{N}$ and $w_{H}^{N}$ depend on the parameters of the model. ${ }^{21}$

\section{Conclusion}

Over the past two decades, the wage structures in both developed and developing countries have changed dramatically. When analyzing the causes of changing wage patterns, economists mostly used static trade models paying relatively little attention to the possible role of outsourcing and innovation dynamics. In addition, a dispropor- 
tionately large number of studies have concentrated on the developments in advanced countries, ignoring the simultaneous changes in developing countries.

In this paper, we have attempted to bridge this gap by examining wage patterns in a unified North-South framework that incorporates the dynamics of technological change and outsourcing. We find that increased trade via increased outsourcing can lead to rising wage inequality in both the North and the South. Hence, rising trade levels can be consistent with the simultaneous increase in wage inequality in both the North and the South. The model also sheds light on the mixed wage inequality trends observed in the South. We find that increased outsourcing raises the Southern skill premium if and only if the skill intensity of production outsourced by the North is larger than that of local Southern production. Our dynamic model also studies the impact of outsourcing on real wages in terms of both level and growth effects. We show that an increase in the extent of outsourcing raises the real wage growth rate for all types of labor in both the North and the South. ${ }^{22}$ Thus, we argue that income distribution consequences of outsourcing must be weighed against positive long-term wage growth effects.

We think that our model provides an analytical framework that can be useful for further empirical research on trade and wages in the context of both developed and developing countries. In addition, our theoretical model can be extended in many directions. For instance, one can endogenize the rate of Southern imitation and check the robustness of the main results. In addition, one can consider a North-North setting in which outsourcing/FDI takes place between two advanced countries and study the implications for labor markets.

\section{References}

Acemoglu, Daron, "Patterns of Skill Premia," Review of Economic Studies 70 (2003):199-230.

Attanasio, Orazio, Pinelopi K. Goldberg, and Nina Pavcnik, "Trade Reforms and Income Inequality in Colombia," Journal of Development Economics 74 (2004):331-66.

Aitken, Brian, Ann Harrison, and Robert E. Lipsey, "Wages and Foreign Ownership: a Comparative Study of Mexico, Venezuela, and the United States," Journal of International Economics 40 (1996):345-71.

Beaulieu, Eugene, Michael Benarroch, and James Gaisford, "Trade Barriers and Wage Inequality in a North-South Model with Technology-Driven Intra Industry Trade," Journal of Development Economics 75 (2004):113-36.

Berman, Eli, John Bound, and Zvi Grilliches, "Changes in the Demand for Skilled Labor within U.S. Manufacturing: Evidence from the Annual Survey of Manufacturers," Quarterly Journal of Economics 109 (1994):367-98.

Borjas, George J. and Valerie A. Ramey, "Foreign Competition, Market Power, and Wage Inequality: Theory and Evidence," Quarterly Journal of Economics 110 (1995):1075-111.

Das, Satya, "Direct Foreign Investment and Relative Wages in a Developing Economy," Journal of Development Economics 67 (2002):55-77.

- "Trade and Relative Wages in a Global Economy," Review of International Economics 11 (2003):397-411.

Dinopoulos, Elias and Paul Segerstrom, "A Schumpeterian Model of Protection and Relative Wages," American Economic Review 89 (1999):450-72.

Dinopoulos, Elias, Costas Syropoulos, and Bin Xu, "Intra-Industry Trade and Wage Inequality," manuscript, University of Florida (2002).

Dinopoulos, Elias and Costas Syropoulos, "Globalization, Factor Endowments and ScaleInvariant Growth,” manuscript, University of Florida (2004).

Dinopoulos, Elias and Peter Thompson, "A Contribution to the Empirics of Endogenous Growth,” Eastern Economic Journal 22 (1996):389-400. 
, "Endogenous Growth in a Cross Section of Countries," Journal of International Economics 51 (2000):335-62.

Feenstra, Robert C., "Integration of Trade and Disintegration of Production in the Global Economy," Journal of Ecomonic Perspectives 12 (1998):31-50.

Feenstra, Robert C. and Gordon H. Hanson, "Foreign Direct Investment and Relative Wages: Evidence from Mexico's Maquiladoras," Journal of International Economics 42 (1997):371-93.

_ , "The Impact of Outsourcing and High Technology Capital on Wages: Estimates for the United States, 1979-1990," Quarterly Journal of Economics 114 (1999):907-40.

"Global Production Sharing and Rising Inequality: a Survey of Trade and Wages," in E.

Kwan Choi and James Harrigan (eds), Handbook of International Trade, Volume 2, Malden,

MA: Blackwell (2004).

Glass, Amy J. and Kamal Saggi, "Innovation and Wage Effects of International Outsourcing," European Economic Review 45 (2001):67-86.

_ "Intellectual Property Rights and Foreign Direct Investment," Journal of International Economics 56 (2002):387-410.

Goldberg, Pinelopi K. and Nina Pavcnik, "Trade, Inequality, and Poverty: What Do We Know? Evidence from Recent Trade Liberalization Episodes in Developing Countries," Brookings Trade Forum, Washington, DC: Brookings Institution Press (2004):223-69.

Grieben, Wolf-Heimo, "A Schumpeterian North-South Growth Model of Trade and Wage Inequality," Review of International Economics 13 (2005):106-28.

Grossman, Gene M. and Elhanan Helpman, Innovation and Growth in the Global Economy, Cambridge, MA: MIT Press (1991).

Katz, Lawrence F. and David H. Autor, "Changes in the Wage Structure and Earnings Inequality," in Orley Ashenfelter and David Card (eds), The Handbook of Labor Economics Volume III, Amsterdam: Elsevier (1999).

Lawrence, Robert Z. and Matthew J. Slaughter, "Trade and U.S. Wages: Great Sucking Sound or Small Hiccup?" Brookings Papers on Economic Activity 2 (1993):161-227.

Leamer, Edward E., "Wage Effects of a U.S.-Mexico Free Trade Agreement," in P. M. Garber (ed.), The Mexico-U.S. Free Trade Agreement, Cambridge: MIT Press, (1993):57-128.

— "Trade, Wages, and Revolving Door Ideas," NBER Working Paper 4716 (1994).

Lundborg, Per and Paul S. Segerstrom, "The Growth and Welfare Effects of International Mass Migration,” Journal of International Economics 56 (2002):177-204.

Markusen, James R. and Anthony J. Venables, "Multinational Firms and the New Trade Theory," Journal of International Economics 46 (1998):183-203.

, "Multinational Production, Skilled Labor and Real Wages," in Richard E. Baldwin and

Joseph F. Francois (eds), Dynamic Issues in Applied Commercial Policy Analysis, New York: Cambridge University Press (1999):138-72.

Neary, J. Peter, "Foreign Competition and Wage Inequality," Review of International Economics 10 (2002):680-93.

Pavcnik, Nina, Andreas Blom, Pinelopi Goldberg, and Norbert Schady, "Trade Policy and Industry Wage Structure: Evidence from Brazil," World Bank Economic Review 18 (2004): 319-44.

Robbins, D., "Evidence on Trade and Wages in the Developing World," OECD Technical Paper No. 119 (1996).

Sayek, Selin and Fuat Şener, "Dynamic Effects of Outsourcing on Wage Inequality and Skill Formation," manuscript, Union College (2001).

Şener, Fuat, "Schumpeterian Unemployment, Trade and Wages," Journal of International Economics 54 (2001):119-48.

Topel, Robert H., "Factor Proportions and Relative Wages: the Supply Side Determinants of Wage Inequality," Journal of Economic Perspectives 11 (1997):55-74.

UNCTAD, World Investment Report: FDI Policies for Development; National and International Perspectives (2003).

Wood, Adrian, North South Trade, Employment and Inequality: Changing Fortunes in a Skill Driven World, Oxford: Clarendon Press (1994). 
$\mathrm{Xu}$, Bin, "The Relationship between Outsourcing and Wage Inequality Under Sector-Specific FDI Barriers," manuscript, University of Florida (2000).

"Trade Liberalization, Wage Inequality and Endogenously Determined Non-traded Goods," Journal of International Economics 60 (2003):417-31.

Zhu, Susan Chun, "Can Product Cycles Explain Skill Upgrading?" Journal of International Economics 66 (2005):131-55.

Zhu, Susan Chun and Daniel Trefler, "Trade and Inequality in Developing Countries: a General Equilibrium Analysis,” Journal of International Economics 65 (2005):21-48.

\section{Notes}

1. See Feenstra and Hanson (2004) and Katz and Autor (1999) for overviews of the wage inequality literature. It is worth mentioning that a series of recent papers seriously challenge the consensus over skill-biased technological change. These papers show that increased trade can lead to rising wage inequality and generate results that are consistent with some of the above empirical regularities. See, among others, Acemoglu (2003), Beaulieu, Benarroch and Gaisford (2004), Das (2002, 2003), Dinopoulos, Syropoulos and Xu (2002), Grieben (2005), Dinopoulos and Segerstrom (1999), Dinopoulos and Syropoulos (2004), Neary (2002), Zhu and Trefler (2005), Zhu (2005), and Xu (2000, 2003). However, none of these papers explicitly model FDI and outsourcing in a dynamic North-South setting.

2. Between 1985-2000, net FDI inflows received by developing countries as a share of their gross fixed capital formation increased from 4\% to 13\% (UNCTAD, 2003). See Feenstra (1998) for an excellent discussion of empirical and stylized evidence on the increasing importance of international outsourcing.

3. See also Attanasio, Goldberg and Pavcnik (2004) who find evidence on the link between trade liberalization and rising wage inequality using Colombian data, and Pavcnik et al. (2004) who report that the link is statistically insignificant for Brazil. See Goldberg and Pavcnik (2004) for an excellent overview of the recent literature on trade and wage inequality in developing countries.

4. Xu (2000) extends Feenstra and Hanson's model by considering an economy with two sectors, each producing a final good. In contrast to Feenstra and Hanson (1997), Xu (2000) finds that international outsourcing does not necessarily generate skill-biased labor demand shifts in either the host or the source economy. He argues that sectoral differences in FDI barriers can be the key in determining the bias of the labor demand shift.

5. Using numerical simulations we show that this condition holds under a wide range of reasonable parameters.

6. It is also possible to generate skill upgrading by endogenizing the skill acquisition decision of workers as in Dinopoulos and Segerstrom (1999) and Beaulieu, Benarroch and Gaisford (2004). In such a setting, individuals respond to increased skill premium by undertaking training and becoming skilled. In an earlier version of the paper Sayek and Şener (2001) we considered a simpler model with endogenous skill acquisition and showed that increased outsourcing can lead to skill upgrading within industries.

7. We assume that each unit of household is infinitely large, and transfers among family members allow each member to realize the same level of consumption regardless of their skill levels. This assumption together with the law of large numbers eliminates aggregate effective uncertainty in household income.

8. See Appendix B (available from the authors) for a discussion of numerical simulations that allow for endogenous outsourcing success probability.

9. This is a pure product cycle mechanism in which technological leadership returns to the North only after production technology becomes sufficiently standardized and production completely takes place in the South. See, among others, the "inefficient followers" regime used in Grossman and Helpman (1991, Chapter 12) and the main model of Glass and Saggi (2002) for settings that adopt such a product cycle framework. 
10. Equation (7) removes the scale-effects feature of the early endogenous growth models, which predicted explosive growth in the presence of positive population growth. It captures the notion that $\mathrm{R} \& \mathrm{D}$ difficulty increases in larger markets due to informational and organizational costs of introducing and replacing new products. In addition, one can justify (7) by arguing that firms devote larger resources to protect their intangible technologies in larger markets where the threat of imitation is stronger. This $R \& D$ difficulty specification originally proposed by Dinopoulos and Thompson (1996) has now been used in a number of studies (see Dinopoulos and Segerstrom (1999) and Şener (2001)). Evaluating the empirical relevance of equation (7) using cross-country data, Dinopoulos and Thompson (2000) argue that this R\&D specification provides "a useful template on which to begin building more sophisticated models of long-run growth."

11. To obtain the unit labor requirements, we consider the implied cost function and use Shephard's lemma along with homogenous of degree one property of the production function.

12. One can assume that when top technology leaks to followers in the South, it also becomes accessible to followers in the North. However, with production costs being higher in North relative to South, it follows that Northern followers cannot effectively compete in the presence of low-cost Southern followers.

13. Recall that that we restrict attention to steady-state outcomes where $v_{F}(\omega, t)-v_{N}(\omega, t)>0$, and thus Northern firms always prefer to be an outsourcing firm whenever such an opportunity arises. Using the profit flow equations for $\pi_{N}$ and $\pi_{F}(12)$ and (13), and the stock market valuation conditions (5) and (6), one can show that $v_{F}>v_{N}$ entails $\left(\lambda-A C^{F}\right) /\left(\lambda-A C^{N}\right)>\delta / \alpha(\rho-n)$. 14. To see this, note that demand for Southern skilled labor coming from Outsourcing is $D L_{F}^{S}=n_{F} \alpha a_{H F}\left(w^{S}\right)(E / \lambda)=\left[f \imath /(f \delta+\imath(f+\delta)] \alpha a_{H F}\left(w^{S}\right)(E / \lambda)\right.$, where (20) is used for $n_{F}$. Using (20) and (17), one can show that $\imath /[f \delta+\imath(f+\delta)](E / \lambda)=\left(1-h^{N}\right) N^{N} /\left[\delta+(1-\alpha) f a_{L N}\left(w^{N}\right)\right]$, which implies that $\partial\left[\imath(f \delta+\imath(f+\delta)](E / \lambda) / \partial w^{N}<0\right.$. Using this result and holding $w^{S}$ constant, one can then show that $\partial D L_{F}^{S} / \partial w^{N}<0$.

15. See Lundborg and Segerstrom (2002, p. 189) for the derivation of this result. It is also possible to interpret technological progress in our model as process innovations aimed at cost reduction. In this case, the price of a product in each industry would fall by $\lambda$ every time a new technology is discovered. At the steady state the rate of decline in the consumption price indexnow without any quality adjustment-would simply equal $I \ln \lambda$, and real wage growth would again equal $g=I \ln \lambda$.

16. More specifically, a higher $\alpha$ raises $w^{N}$ and thereby triggers two opposing effects on the demand for Northern unskilled labor: a negative effect via decreasing $E$ and a positive effect via increasing the unit labor requirement $a_{L F}^{N}$. The net impact is a fall in the demand for unskilled labor. To restore equilibrium, there must be a rise in the measure of industries $n_{N}+n_{F}$ through a rise in $l$.

17. To see the change in $E$, totally differentiate equation (21). This gives $d E / d \alpha=\partial E / \partial \alpha+$ $\left(\partial E / \partial w^{N}\right)\left(d w^{N} / d \alpha\right)><0$.

18. In each labor market, the effects of an increase in $f$ materialize via three channels. First, a higher $f$ raises $n_{F}$ and $n_{S}$, boosting the demand for Southern labor. Second, a higher $f$ reduces the relative demand for unskilled labor in the North, requiring a rise in $E$ to restore equilibrium. The higher $E$, in turn, raises the demand for Southern labor. Third, a higher $f$ generates an increase in $l$ via equation (22) and thereby reduces $n_{F}$ and raises $n_{S}$. The former reduces the Southern labor demand, whereas the latter raises it. The combined impact of the three forces identified above is an increase in the Southern labor demand.

19. The indirect effect is already analyzed in the discussion of (22). To analyze the direct effect, we focus on Northern unskilled labor market equilibrium given by (17). First, a higher $f$ reduces the relative demand for Northern unskilled labor. This requires a rise in $E$ for equilibrium to be restored [see equation (21)]. The higher $E$, in turn, raises the absolute demand for unskilled labor in the North. Second, a higher $f$ increases $n_{F}$ and reduces $n_{N}$. The job gains emanating from the Outsourcing industries are dominated by the job losses coming from the Northern industries (note that $\partial\left(n_{N}+n_{F}(1-\alpha)\right) / \partial f<0$ by industry share equations (20)). Consequently, the second 
effect works to reduce the demand for Northern unskilled labor. The combined impact of the two effects is a fall in Northern unskilled employment; thus, $\imath$ must rise to restore equilibrium. 20. To see the change in $E$, totally differentiate equation (21) to obtain $d E / d f=\partial E / \partial f+$ $\left(\partial E / \partial w^{N}\right)\left(d w^{N} / d f\right)><0$.

21. With regards to level effects in the North, numerical simulations indicate that increased outsourcing-driven by either an increase in $\alpha$ or an increase in $f$-in general raises the wage levels of both skilled and unskilled labor.

22. It should be noted that this is established analytically in the case of an increase in $\alpha$ and via numerical simulations in the case of an increase in $f$. 